\title{
Development in Direct Methanol - Oxygen Fuel Cell (DMFC)
}

\author{
Mr. Nirmal Ramkrishna Joshi.
}

\begin{abstract}
This research paper describes recent developments in methanol-oxygen fuel cell or direct methanol fuel cells (DMFCs). An application of DMFCs in portable power sources and in hybrid electrical vehicles has recently been envisaged. The section is particularly focused on the electro catalysis of the methanol oxidation reaction and oxygen electro reduction. In this regard, some aspects of the electro catalysis of oxygen reduction in the presence of methanol crossover have been treated. The technology section deals with the development of both components and devices. The recent efforts in developing DMFC stacks for both portable and electrotraction applications are studied. The current status of the technology in this field is presented and some important technical challenges are been discussed.
\end{abstract}

(Key words-: Nafion membrane, Proton exchange membrane, Membrane electrode assembly, bipolar plate).

\section{Introduction}

In a fuel cell electrical energy is obtained from oxygen and a fuel that can be oxidised The essential process in a fuel cell is

Fuel + Oxygen $\rightarrow$ Oxidation product + Electricity

Methanol - oxygen fuel cell are powered by pure methanol. In the early 1960s, the mechanism of this reaction was the subject of many studies in different countries. Still, the specific power attained was quite small. Only in the mid 1990s, after the great successes achieved in the development of hydrogen-oxygen fuel cells with the proton-conducting ion exchange membrane, was a breakthrough reached in the development of fuel cells with direct (without preliminary conversion) oxidation of methanol. Fuel cells of this type were now called "direct-methanol fuel cells" (DMFC). The design of modern DMFCs is very similar to the design of protonexchange-membrane fuel cells. The membranes (Nafion) and catalysts (Platinum) are used.

\section{Direct Methanol Fuel Cell (DMFC)}

Direct Methanol Fuel Cell (DMFC) is a fuel cell that runs directly on methanol (or various liquid fuels) without having to first convert those fuels into hydrogen gas. It consists of two electrodes separated by a proton exchange membrane (PEM) and connected via an external circuit that allows the conversion of free energy from the chemical reaction of methanol with air or oxygen to be directly converted into electrical energy.

The direct methanol fuel cell is a proton exchange membrane (PEM) fuel cell that is fed with an aqueous solution of methanol.

The two catalytic electrodes where the methanol oxidation (anode) and the oxygen reduction (cathode) are separated by a membrane which conducts protons from anode to cathode, while other compounds diffusion is blocked. The combination of electrodes and membranes is called membrane electrode assembly (MEA). MEA was prepared with Pt/Ru black at anode and Pt black cathode on either side of a Nafion membrane. Each electrode is made of a gas diffusion layer and a catalytic layer (Figure 1).

Membrane Nafion was created by addition of sulfonic acid groups into the bulk polymer matrix of Teflon. These sites have strong ionic properties and act as proton exchange sites.

Aqueous methanol is fed at the anode side. It diffuses through the diffusion layer to the catalytic layer where it is electrochemically oxidized into mainly carbon dioxide, protons and electrons.

Protons formed during this reaction diffuse through the Nafion membrane to the cathode catalytic layer. They participate in oxygen reduction to form water at cathode side. Oxygen may be pure but can also come from air.

Electrons are collected by graphite bipolar plates which are the two poles of the cell.

The structure of the cell is described in Figure 1. 


\section{Reactions}

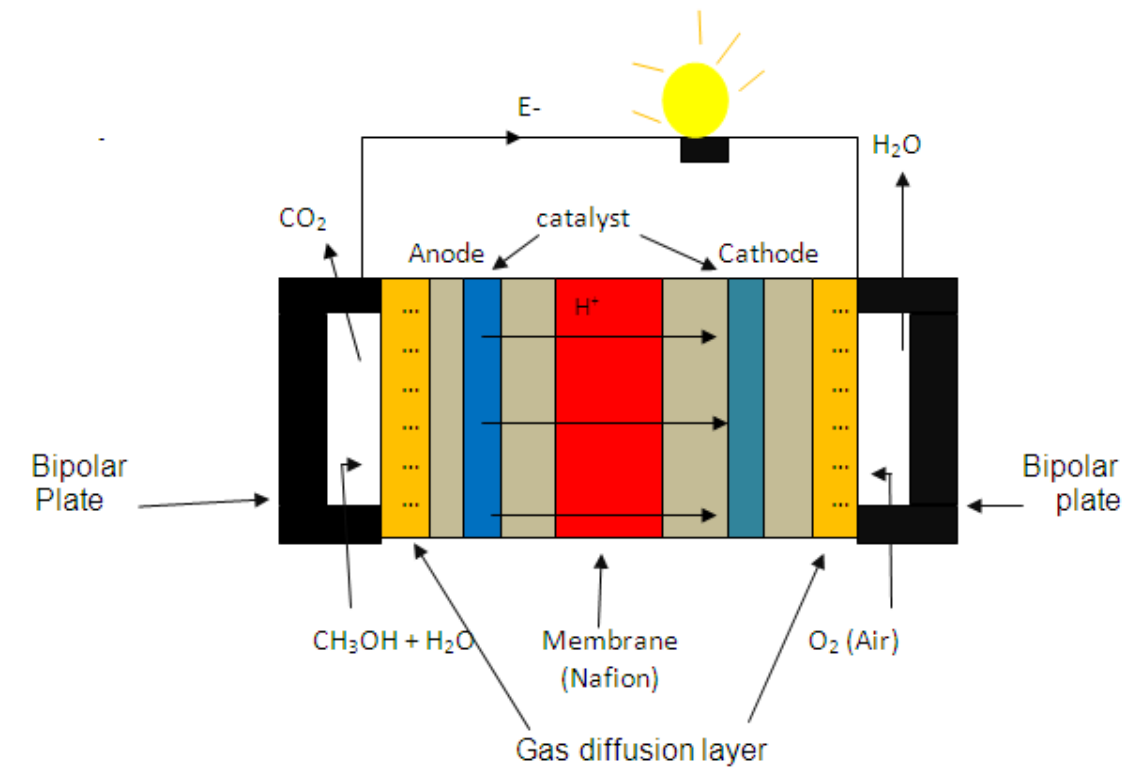

Figure I: Direct Methanol - Oxygen Fuel Cell (DMFC).

$$
\begin{array}{llcc}
\text { Anode reaction -: } \mathrm{CH}_{3} \mathrm{OH}+7 \mathrm{H}_{2} \mathrm{O} & \rightarrow & \mathrm{CO}_{2}+6 \mathrm{H}_{3} \mathrm{O}^{+}+6 \mathrm{e}^{-} \mathrm{E}^{0}=0.02 \mathrm{~V} \\
\text { Cathode reaction }-:{ }^{3}{ }_{2} \mathrm{O}_{2}+6 \mathrm{H}_{3} \mathrm{O}^{+}+6 \mathrm{e}^{-} & \rightarrow & 9 \mathrm{H}_{2} \mathrm{O} & \mathrm{E}^{0}=1.23 \mathrm{~V} \\
& & & \\
\hline \text { Overall reaction -: } \mathrm{CH}_{3} \mathrm{OH}+{ }^{3} /{ }_{2} \mathrm{O}_{2} & \rightarrow & \mathrm{CO}_{2}+2 \mathrm{H}_{2} \mathrm{O} & \mathrm{E}^{0}=1.21 \mathrm{~V}
\end{array}
$$

At anode, the methanol is oxidized into carbon dioxide and six protons (as hydronium ions) plus six electrons. The six protons formed react at the cathode with oxygen to form water.

The overall reaction looks like a combustion reaction and is thus sometimes referred to as cold combustion. Actually the cell is a mean to control this reaction and use it to produce current directly.

The standard cell voltage for a DMFC at $25^{\circ} \mathrm{C}$ is $1.21 \mathrm{~V}$. However, this potential is never obtained in reality. The open circuit potential is usually about 0.6 to $0.8 \mathrm{~V}$.

\section{- Slow electro-oxidation kinetics}

\section{Issues in DMFC}

Various surface intermediates are formed during methanol electro-oxidation.

Methanol is mainly decomposed to $\mathrm{CO}$ which is then further oxidized to $\mathrm{CO}_{2}$. Other $\mathrm{CO}$ like species are also formed: $\mathrm{COH}$ ads, $\mathrm{HCO}$ ads, $\mathrm{HCOO}$ ads Principle by-products are formaldehyde and formic acid. Some of these intermediates are not readily oxidizable and remain strongly adsorbed to the catalyst surface. Consequently, they prevent fresh methanol molecules from adsorbing and undergoing further reaction. Thus electro-oxidation of intermediates is the rate limiting step.

This poisoning of the catalyst surface seriously slows down the oxidation reaction.

Besides, a small percentage of the intermediates desorbs before being oxidized to $\mathrm{CO}_{2}$ and hence reduce fuel efficiency but undergoing incomplete oxidation.

Thus, a very important challenge is to develop new electro catalysts that inhibit the poisoning and increase the rate of the reaction. At the same time, they should have a better activity toward carbon dioxide formation.

\section{- Methanol Crossover}

Description: In DMFC the membrane is partially permeable by methanol dissolved in the aqueous solution. For this reason, some of the methanol penetrates from the anode part of the cell through the membrane into the cathode part. This phenomenon is called "methanol crossover". This methanol is directly oxidized on the platinum catalyst by gaseous oxygen without producing useful electrons. This has two consequences: (i) a substantial part of methanol is lost for the electrochemical reaction, and (ii) the potential of the oxygen electrode is shifted to lower positive values and therefore the operating voltage of the fuel cells is diminished.

In DMFC, the fuel diffuses through Nafion membrane. Methanol that crosses over reacts directly with oxygen at the cathode. Resulting in an internal short circuiting and consequently a loss of current. similar to anode.

Besides, the cathode catalyst, which is pure platinum, is fouled by methanol oxidations intermediates 
Simple solutions to prevent crossover:

Crossover is enhanced by the concentration and pressure gradient between anode and cathode. It can be easily limited by using a low methanol concentration in the anode feed solution and by increasing cathode pressure in a certain measure. A compromise should be found for the concentration. It should be small enough to reduce crossover as much as possible but also supply the anode catalytic layer with enough methanol to produce an acceptable current density.

The effect of a barrier layer was investigated to reduce crossover. Finally, zirconia and silica nanocomposite membranes were tested instead of Nafion and found to reduce crossover.

\section{Advantages}

1. Methanol can be refueled quickly and simply.

2. Methanol is arguably the most efficient carrier of hydrogen.

3. The simplicity of methanol storage drastically reduces the weight of the system.

4. Ideal for low power-density, but high energy-density applications.

\section{Disadvantages}

1. Fuel can cross electrolyte without reacting, reducing efficiency.

2. Low power-density.

3. Methanol can corrode various parts of the fuel cell.

4. Methanol is toxic and flammable, much like gasoline.

\section{Applications}

A potential area of application for DMFCs is low-power (up to $20 \mathrm{~W}$ ) power sources for electronic equipment, such as notebooks, video cameras, DVD-players, cell phones, medical devices, etc. At this time, the application of DMFCs as power sources for electric vehicles is very remote.

Substantial progress are also made in the design and prototyping of DMFC stacks for portable and auxiliary power applications. Three generations of highly efficient and lightweight 11-W stacks were developed for the operation at a design voltage of $0.55 /$ cell. Four units from the last generation were supplied to Aerospace $\&$ Technologies Corporation and prototypes for the military are also available.

\section{References;}

[1]. R. Dillon, S. Srinivasan, A. S. Aricò and V. Antonucci "International activities in DMFC R\&D: status of technologies and potential applications"

[2]. Michel Broussely and Graham Archdale "Li-ion batteries and portable power source prospects for the next 5-10 years" Journal of Power Sources, Volume 136, Issue 2, 1 October 2004, Pages 386-394

[3]. Gogel , T. Frey, Zhu Yongsheng, K. A. Friedrich, L. Jörissen and J. Garche "Performance and methanol permeation of direct methanol fuel cells: dependence on operating conditions and on electrode structure"

[4]. Journal of Power Sources, Volume 127, Issues 1-2, 10 March 2004, Pages 172-180

[5]. G. Q. Lu and C. Y. Wang "Electrochemical and flow characterization of a direct methanol fuel cell"

[6]. Journal of Power Sources, Volume 134, Issue 1, 12 July 2004, Pages 33-40 Zhaobin Wei, Suli Wang, Baolian Yi, Jianguo Liu, Likang Chen, WeiJiang Zhou,

[7]. Wenzheng Li and Qin Xin "Influence of electrode structure on the performance of a direct methanol fuel cell" Journal of Power Sources, Volume 106, Issues 1-2, 1 April 2002, Pages 364-369

[8]. H. Yang and T.S. Zhao "Effect of anode flow field design on the performance of liquid feed direct methanolfuel cells" Electrochimica Acta, In Press, Corrected Proof, Available online 12 January 2005,

[9]. K. Sundmacher, T. Schultz, S. Zhou, K. Scott, M. Ginkel and E. D. Gilles "Dynamics of the direct methanol fuel cell (DMFC): experiments and model-based analysis" Chemical Engineering Science, Volume 56, Issue 2, January 2001, Pages 333-341

[10]. Lindermeir, G. Rosenthal, U. Kunz and U. Hoffmann"On the question of MEA preparation for DMFCs"

[11]. Journal of Power Sources, Volume 129, Issue 2, 22 April 2004, Pages 180-187

[12]. G. Q. Lu and C. Y. Wang "Electrochemical and flow characterization of a direct methanol fuel cell" Journal of Power Sources, Volume 134, Issue 1, 12 July 2004, Pages 33-40

[13]. Jain and Jain Text book of Engineering chemistry, page303-305. S.S. Dara Text book of engineering chemistry, page 736-739 